\title{
The Role of Third Trimester Oxytocin Level in Predicting Postpartum Depression Symptoms among Jordanian Mothers.
}

\author{
Hasan RAWASHDEH ( $\sim$ hmrawashdeh@just.edu.jo ) \\ Jordan University of Science and Technology \\ Zahra ALALWANI \\ King Abdullah University Hospital \\ Amer SINDIANI \\ Jordan University of Science and Technology \\ Rana ALODETALAH \\ King Abdullah University Hospital \\ Mohammad ALQUDAH \\ Jordan University of Science and Technology
}

\section{Research Article}

Keywords: Postpartum depression, Oxytocin, EPDS, Prediction

Posted Date: February 8th, 2021

DOI: https://doi.org/10.21203/rs.3.rs-172460/v1

License: (c) (i) This work is licensed under a Creative Commons Attribution 4.0 International License. Read Full License 


\section{Abstract}

Background: About one in five women suffer from postpartum depression, placing it the leading complication during childbirth. Oxytocin has been suggested to play a key role in modulating maternal behaviour and stress-related disorders. However, there is little evidence to support its role in predicting postpartum depression. Our aim is to investigate the relationship between serum oxytocin level in the third trimester and early-onset postpartum depression symptoms and whether oxytocin is capable of predicting postpartum depression symptoms.

Methods: A total of 172 healthy pregnant women participated in this cross-sectional descriptive study. The serum oxytocin level was measured between 34 and 37 weeks. A validated Edinburgh Postnatal Depression Scale (EPDS) was used to assess symptoms of depression four to six weeks postpartum. Participants with EPDS scores of 13 or more were considered having depressive symptoms. SPSS version 23 was used for data analysis. Descriptive statistics were provided. Independent sample t-test and Pearson r were used to examine differences in depression scores between selected demographic, psychosocial, and clinical variables. The level of significance for all analyses was set at $a=0.05$.

Results: $8 \%$ of participants have scored 13 or above at the EPDS. Pearson $r$ indicated that there was no correlation between EPDS scores and oxytocin level $r(170)=0.10, p=0.23$. Furthermore, there was no correlation between EPDS scores and oxytocin level among women with a lifetime history of depression, $r(43)=-0.13, p=0.37$. Independent t-test has shown that participants with low education, low income, previous history of depression, positive family history of depression, positive family issues and absent emotional family support have scored significantly higher on EPDS scores than their counterparts. The association with a previous lifetime history of depression was noticeable $t(170)=\quad-4.40, p<0.001$.

Conclusions: There was no relation between late antenatal third trimester serum oxytocin level and early onset postpartum depression symptoms. Third trimester serum oxytocin level alone was not capable of predicting early onset postpartum depression.

\section{Background.}

Pregnancy is a major life event that is inevitably accompanied by social, psychological, and hormonal changes. In fact, from a psychological point of view, it is considered the most complex event in human experience. Pregnancy can trigger a wide range of emotions from transient mood liability to severe depressive episodes.

Traditionally post-partum psychiatric disorders (PPPD) have been classified into postpartum blues, postpartum psychosis, and postpartum depression. Postpartum depression (PPD) is the most common form and is defined as a depressive episode, starting within 6 months after childbirth, that meets the DSM-IV criteria for a major depressive episode, without psychotic features. [1]

In Jordan, the incidence of PPD is about $22 \%$, which is comparable to the nearby countries. [2-4] This places PPD one of the most common and most serious public health problems, since it is a major contributor of the $8 \%$ maternal deaths related to mental health problems.[5] Moreover, infants of PPD mothers are at a great risk of their physical, emotional, cognitive, and interpersonal problems in their later lives.[6]

PPD is often underdiagnosed and untreated for many reasons related to maternal underreporting of symptoms, poor awareness of the medical care providers, and limited sensitivity of the available screening tools.[7] This has stimulated researchers to investigate specific biomarkers that can predict and identify PPD objectively like the Leptin level, Brain-Derived Neurotrophic Factor(BDNF), LH:FSH ratio, and oxytocin level.[8-11]

Oxytocin is a peptide hormone synthesized in the supraoptic and paraventricular nuclei of the hypothalamus and released into the bloodstream via the posterior pituitary gland. A large body of research supports the role of oxytocin as a social hormone in humans.[12] However, the available evidence of the effect of antenatal oxytocin on PPD is not robust enough to be applied clinically as a biologic marker nor as a treatment option.[13] This study aims to investigate the association between serum oxytocin concentration in the third trimester and postpartum depression symptoms in the early postnatal period and whether antenatal oxytocin level is capable of predicting postpartum depression symptoms.

\section{Methods.}

The sample consisted of women having regular antenatal care at King Abdulla University Hospital (KAUH), a tertiary hospital located in Irbid, at the north of Jordan. Only women with confirmed gestational age by early first trimester scan between 11 and 14 weeks using Crown Rump Length (CRL) were included in this cross sectional descriptive study.

Sample size was computed utilizing $G^{*}$ power software.[14] A power level of 0.80 , an alpha level of 0.05 and an effect size of 0.5 for independent $t$ test were used to calculate sample size. The estimated sample size was 128 based on the previous parameters. To handle the problem of participants withdrawal and missingdata, anadditional30participantswereadded $\rightarrow$ haveat $\leq * 158$ participants $\in$ thef $\in$ alsamp $\leq$ size. Thestudy s final sample size was 172 participants.

\subsection{Subjects}

Candidate participants were women having a singleton pregnancy, between 34 and 37 weeks of gestation, not known to have chronic medical illnesses nor current mental illnesses, and not known to have fetal abnormalities whether growth, structural or chromosomal.

Loading [MathJax]/jax/output/CommonHTML/jax.js 
All candidates were given the opportunity to participate in the study during their routine third trimester antenatal visits. A full description of the study design, requirements of the study, and the purpose of the work was delivered to them through a designated interviewer. The interviewer was a medical practitioner who provided instant answers for the candidates' inquiries before completing the written informed consent of participation and collected brief socioeconomic data.

Over 16 months' duration, starting in September 2018 and ending by December 2019, 211 participants completed their consents for participation and were admitted to the study. 14 of them declined providing blood sample and asked to be withdrawn. 197 blood samples were collected. Follow up was lost with 24 participants because they provided a wrong contact details or they failed to answer within the specific time period. There was one case of early neonatal death after one week of delivery where the entry was removed. The final complete sample was consisted of 172 participants where they completed the consent of participation, provided blood sample for serum oxytocin concentration, and answered our phone call after 4 to 6 weeks of their delivery of live singleton newborn and completed the Edinburgh Postnatal Depression Scale (EPDS) by the same interviewer. A flowchart of participants is displayed in Fig. 1.

A validated translation of Edinburgh Postnatal Depression Scale (EPDS) into Arabic language was used to assess postpartum depression symptoms. [15] A total of 10 items, dealing with typical PPD symptoms were answered on a 4-point scale. Women who scored 13 and above were considered positive for depression.

Ethical approval was gained by the IRB committee at King Abdulla University Hospital on September 2018 under serial No.(GM7601). Demographic and clinical data were collected from medical records of participants while socioeconomic data were completed by the participants themselves during signing the consent.

\subsection{Sample collection and storage}

All experimental work took place at the research laboratory. All safety protocols were applied to all procedures. Biohazardous materials were disposed according to the bio-safety guidelines regulations.

Samples were collected by Vacutainer technique into one plain tube used to separate serum for Enzyme Linked Immunosorbent Assay (ELISA) for oxytocin. All samples were collected between 11:00 and 15:00. Samples were centrifuged at 4000 rpm for 7-10 minutes. Serum from plain tubes transferred into 2 clearly labelled Eppendorf tubes. All aliquots were stored in deep freezer at $-80^{\circ} \mathrm{C}$.

\subsection{Enzyme-Linked Immunosorbent Assay (ELISA)}

Preparation of reagents, standards, diluents, and buffers took place before starting ELISA procedure exactly as mentioned in the kits' manual. Competitive ELISA technique was conducted using kits from Ray Biotech company (Georgia, USA).

Series of consecutive steps were done using fully automated ELISA device " Elisys Uno " by HUMAN company (Wiesbaden, Germany) as following:

1- Micro well strips were prepared and kept at room temperature.

2- Then we prepared assay diluent B, anti-oxytocin antibody, standards, and samples.

3- Anti-oxytocin antibody added to all wells, and incubated for 1.5 hours (varies between kits) at room temperature.

4- Wells were washed with washing buffer for four times to remove excess amount of antibodies, then standards and samples added to their assigned position, and incubated for two and half hours at room temperature.

5- Wells were washed again with washing buffer for four times to remove excess amount of standards and samples. Streptavidin-HRP was added and incubated for 45 minutes (varies between kits) at room temperature.

6- Wells were washed with washing buffer for four times to remove excess amount of Streptavidin-HRP, then TMB Substrate Solution was added and incubated for thirty minutes at room temperature avoiding exposure to direct light.

7- Stop solution was added to all wells and read immediately on micro well ELISA reader spectrophotometer using $450 \mathrm{~nm}$ as the primary wave length. Then absorbance readings underwent a series of mathematical equations to generate standard curve to calculate sample results.

\subsection{Statistical Analysis}

Data were analyzed using the Statistical Package for Social Science (SPSS) version 23 (SPSS, Inc, Chicago, III). Descriptive statistics including mean (M), standard deviation (SD) and frequency (\%) were utilized to describe the sample. Independent sample t-test was used to examine differences in depression scores based on selected demographic, psychosocial and clinical variables. Pearson product moment-correlation was used to assess the relationship between EPDS and age, maternal age and oxytocin serum concentration. The level of significance for all analyses was set at $a=0.05$.

Edinburgh Postnatal Depression Score (EPDS) was normally distributed where the skewness level was 0.1. No missing or outlier values were detected in the analyzed data.

Loading [MathJax]/jax/output/CommonHTML/jax.js 


\section{Results.}

\subsection{Sample Characteristics}

The mean age for the participants in the study was $31(\mathrm{SD}=4.96)$ ranging from 18-41 years old. The majority of participants were well educated as more than three quarter of them had bachelor degree or above $(n=134)$. Although half of the participants were employed $(n=86)$, most of them had total family monthly income of less than 1000 Jordanian Dinars $(\approx 1400$ US Dollars $)(n=128)$. More than half of the participants gave birth a newborn of a female gender $(n=91)$. Results of sample characteristics including socio-demographic variables are presented in Table 1.

As shown in Table 1, fifty-three participants have scored 13 or above at the EPDS revealing a prevalence of probable PPD among our cohort to be 30.8 \%. The mean score of participants at EPDS was $9.98(S D=5.13)$, ranging from 0 to 24.

About a quarter $(26 \%, n=45)$ had a previous history of depression, while only $4 \%$ had family history of depression $(n=7)$. The majority of participants $(90 \%, n=155)$ felt that they had adequate family support and another $90 \%$ were satisfied by the health care services received during their stay in the hospital. Only $3.5 \%$ of the sample had family issues $(n=6)$.

Seventy-six percent of the pregnancies were planned $(n=131)$. Almost one-fifth of the sample were primi gravid women $(n=34)$. The mean gestational age of delivery (in weeks) was $37.80(S D=1.32)$ ranging from 35 to 41 . About half of the deliveries were elective caesarean section $(n=85), 12.7 \%$ were emergency caesarean section $(n=22)$, and $37 \%$ were vaginal deliveries $(n=64)$. Only $8 \%$ of the sample had induced labor and syntocinon infusion was used in $14.5 \%$ of the sample $(n=25)$. Postpartum hemorrhage complicated six deliveries.

Among the 64 participants who delivered vaginally, 79\% didn't receive any medication for pain management. Episiotomy and repair of perineal tears were performed for $15 \%(n=26)$ and $26 \%(n=44)$ of the sample respectively.

The mean oxytocin serum concentration was $195.10(\mathrm{ng} / \mathrm{ml})$ ranging from 10.38 to 498.78 . Only $1.2 \%$ had gestational diabetes $(\mathrm{n}=2)$. Results of sample characteristics including clinical variables are presented in Table 1.

\subsection{EPDS scores and selected sociodemographic and clinical factors.}

As illustrated in Table 2, Independent t-test has shown that there was a statistically significant difference $t(170)=-4.40$, $p<0.001$ was between the mean EPDS score of participants with a previous lifetime history of depression $(M=12.73, S D=4.76)$ and participants without previous history of depression $(M=9.01, S D=4.91)$. Also, there was a statistically significant association between the mean EPDS score and the level of education, level of income, family history of depression, family issues and emotional family support.

While Table 3 demonstrated that there was no relationship between EPDS score with gestational age of delivery nor maternal age using Pearson $r$ test.

In short, participants with low education, low income, previous history of depression, positive family history of depression, positive family issues and absent emotional family support have scored significantly higher on EPDS score than their counterparts.

\subsection{EPDS scores and serum oxytocin concentration.}

Pearson $r$ indicated that there was a non-significant direct correlation between EPDS scores and serum oxytocin concentration, as shown in Table 3.

On the other hand, Pearson $r$ indicated that there was a non-significant inverse correlation $r(43)=-0.13, p=0.37$ between the EPDS scores and the serum oxytocin concentration among women with a lifetime history of depression. As previous history of depression has defined an association with EPDS among our cohort. 
Table 1

Sample characteristics for the participants. mean (M); standard deviation (SD) and percent (\%). (N = 172)

\begin{tabular}{|c|c|c|c|c|}
\hline Variable & Range & $M(S D)$ & $\mathbf{n}$ & $\%$ \\
\hline \multicolumn{5}{|l|}{ Demographic variables } \\
\hline Age & $18-41$ & $31.02(04.96)$ & 172 & 100 \\
\hline \multicolumn{5}{|l|}{ Employment } \\
\hline Employed & & & 86 & 50 \\
\hline House wife & & & 86 & 50 \\
\hline \multicolumn{5}{|l|}{ Income } \\
\hline Low & & & 128 & 74.70 \\
\hline High & & & 044 & 25.60 \\
\hline \multicolumn{5}{|l|}{ Gender of the baby } \\
\hline Male & & & 81 & 47.10 \\
\hline Female & & & 91 & 52.90 \\
\hline \multicolumn{5}{|l|}{ Level of education } \\
\hline School & & & 25 & 14.50 \\
\hline Diploma & & & 13 & 07.60 \\
\hline Bachelor & & & 121 & 70.30 \\
\hline Master & & & 11 & 06.40 \\
\hline Philosophy Degree & & & 2 & 01.20 \\
\hline \multicolumn{5}{|l|}{ Social and Psychological variables } \\
\hline Edinburgh Postnatal Depression Score (EPDS) & $0-24$ & $9.98(5.13)$ & 172 & 100 \\
\hline \multicolumn{5}{|l|}{ EPDS score } \\
\hline$<13$ & & & 119 & 69.20 \\
\hline$\geq 13$ & & & 053 & 30.80 \\
\hline \multicolumn{5}{|l|}{ Previous history of depression } \\
\hline Yes & & & 045 & 26.20 \\
\hline No & & & 127 & 73.80 \\
\hline \multicolumn{5}{|l|}{ Family history of depression } \\
\hline Yes & & & 007 & 04.10 \\
\hline No & & & 165 & 95.90 \\
\hline \multicolumn{5}{|l|}{ Family emotional support } \\
\hline Yes & & & 155 & 90.10 \\
\hline No & & & 017 & 09.90 \\
\hline \multicolumn{5}{|l|}{ Family Issues } \\
\hline Yes & & & 006 & 03.50 \\
\hline No & & & 166 & 96.50 \\
\hline \multicolumn{5}{|l|}{ Satisfied with health care } \\
\hline Yes & & & 155 & 90.10 \\
\hline No & & & 007 & 09.90 \\
\hline \multicolumn{5}{|l|}{ Clinical variables } \\
\hline Serum Oxytocin concentration (ng/ml) & $10.38-498.78$ & $195.10(123.62)$ & 172 & 100 \\
\hline
\end{tabular}




\begin{tabular}{|c|c|c|c|c|}
\hline Variable & Range & $M(S D)$ & $\mathbf{n}$ & $\%$ \\
\hline Gestational age (weeks) & $0035-0041$ & $037.80(001.31)$ & & \\
\hline \multicolumn{5}{|l|}{ Planned pregnancy } \\
\hline Yes & & & 131 & 76.20 \\
\hline No & & & 041 & 23.80 \\
\hline \multicolumn{5}{|l|}{ Parity } \\
\hline Prim gravid & & & 034 & 19.80 \\
\hline Multi gravida & & & 138 & 80.20 \\
\hline \multicolumn{5}{|c|}{ Presence history of miscarriages } \\
\hline Yes & & & 047 & 27.30 \\
\hline No & & & 125 & 72.70 \\
\hline \multicolumn{5}{|l|}{ Mode of delivery } \\
\hline Caesarean section & & & 108 & 62.80 \\
\hline Vaginal delivery & & & 064 & 37.20 \\
\hline \multicolumn{5}{|c|}{ Analgesics use during labour } \\
\hline Yes & & & 036 & 56.25 \\
\hline No & & & 028 & 43.75 \\
\hline \multicolumn{5}{|l|}{ Episiotomy } \\
\hline Yes & & & 026 & 40.62 \\
\hline No & & & 038 & 59.38 \\
\hline \multicolumn{5}{|l|}{ Perineal suturing } \\
\hline Yes & & & 044 & 68.75 \\
\hline No & & & 020 & 31.25 \\
\hline \multicolumn{5}{|l|}{ Post-partum haemorrhage } \\
\hline Yes & & & 006 & 03.50 \\
\hline No & & & 166 & 96.50 \\
\hline \multicolumn{5}{|l|}{ Gestational diabetes } \\
\hline Yes & & & 002 & 01.20 \\
\hline No & & & 170 & 98.80 \\
\hline \multicolumn{5}{|l|}{ Induced labor } \\
\hline Yes & & & 013 & 07.60 \\
\hline No & & & 159 & 92.40 \\
\hline
\end{tabular}


Table 2

Independent t-test to examine the difference in post-partum depression based on selected demographic, social and psychological, and clinical variables. $(\mathrm{N}=172)$

\begin{tabular}{|c|c|c|c|}
\hline Variable & $M(S D)$ & $t(170)$ & $P$-value \\
\hline Employment & & 1.20 & 0.23 \\
\hline Employed & $09.51(5.09)$ & & \\
\hline Non employed & $10.45(5.15)$ & & \\
\hline Income & & 2.17 & 0.03 \\
\hline Low & $10.48(4.95)$ & & \\
\hline High & $08.55(5.42)$ & & \\
\hline Gender of the newborn & & 1.08 & 0.27 \\
\hline Male & $09.53(4.78)$ & & \\
\hline Female & $10.38(5.41)$ & & \\
\hline Education & & 2.50 & 0.01 \\
\hline Below Bachelor & $12.32(5.46)$ & & \\
\hline Bachelor and above & $09.59(4.98)$ & & \\
\hline Previous history of depression & & -4.40 & $<0.001$ \\
\hline Yes & $12.73(4.76)$ & & \\
\hline No & $09.01(4.91)$ & & \\
\hline Family history of depression & & -2.45 & 0.01 \\
\hline Yes & $14.57(5.25)$ & & \\
\hline No & $9.79(5.05)$ & & \\
\hline \multicolumn{4}{|l|}{ Family emotional support } \\
\hline Yes & $9.71(5.02)$ & 2.12 & 0.03 \\
\hline No & $12.47(5.60)$ & & \\
\hline \multicolumn{4}{|l|}{ Family Issues } \\
\hline Yes & $15.50(5.71)$ & -2.73 & 0.007 \\
\hline No & $9.78(5.01)$ & & \\
\hline Satisfied with health care & & -0.73 & 0.46 \\
\hline Yes & $10.08(5.12)$ & & \\
\hline No & $09.12(5.27)$ & & \\
\hline Planned pregnancy & & 1.49 & 0.13 \\
\hline Yes & $09.66(5.01)$ & & \\
\hline No & $11.02(5.43)$ & & \\
\hline Parity & & 1.81 & 0.07 \\
\hline Prim gravid & $08.56(4.56)$ & & \\
\hline Multi gravida & $10.33(5.22)$ & & \\
\hline Previous history of miscarriages & & -0.46 & 0.64 \\
\hline Yes & $10.28(5.05)$ & & \\
\hline No & $09.87(5.17)$ & & \\
\hline Mode of delivery & & -1.04 & 0.29 \\
\hline Caesarean section & $10.30(5.36)$ & & \\
\hline “’aginal delivery & $9.45(4.70)$ & & \\
\hline
\end{tabular}




\begin{tabular}{|llll|}
\hline Variable & M(SD) & $\mathbf{t ( 1 7 0 )}$ & $P$-value \\
\hline Post-partum haemorrhage & & -0.65 & 0.51 \\
\hline Yes & $11.33(5.27)$ & & \\
\hline No & $09.93(5.13)$ & & \\
\hline Induced labour & & 0.99 & 0.31 \\
\hline Yes & $08.62(5.47)$ & & \\
No & $10.09(5.10)$ & & \\
\hline
\end{tabular}

Table 3

Pearson Product-moment correlation to assess the correlation between Edinburgh Postnatal Depression Score (EPDS)with maternal age, serum oxytocin concentration, and gestational age of delivery. $(\mathrm{N}=172)$

\begin{tabular}{|lll|}
\hline Variable & EPDS scores r & $P$-value \\
\hline Maternal age & 0.02 & 0.76 \\
\hline Oxytocin serum concentration & 0.10 & 0.23 \\
\hline Gestational age of delivery & 0.05 & 0.54 \\
\hline
\end{tabular}

\section{Discussion.}

Our thesis was to use serum oxytocin concentration in the third trimester to predict PPD symptoms in the early postnatal period. We hypothesized that we can draw an inverse correlation between oxytocin concentration in the third trimester and postpartum depression symptoms in the early postnatal period, relying on the available data from older studies. $[16,17]$ Our aim was to suggest antenatal oxytocin as a specific biomarker capable of predicting PPD in the early postnatal period. By doing this, we would be able to identify potential candidates for PPD and we would treat them even before symptoms development; in order to reduce the adverse effects of PPD symptoms on the mother and on her newborn as well.

Unlike our proposed assumption, we found no significant association between endogenous antenatal serum oxytocin concentration in the late third trimester (34 to 36 weeks) and early postpartum depression symptoms (4 to 6 weeks). Our results partially agreed with (Massey, 2016) who at first found no correlation between antenatal oxytocin and PPD symptoms. But, a direct significant association appeared only among women with a life time history of depression.[18] In fact, when we tested oxytocin with postpartum depression symptoms among women with a lifetime history of depression, similar to (Massey, 2016), we found a non-significant inverse correlation.

Regarding (Skrundz, 2011), their study was the first to show a significant invers correlation between antenatal oxytocin with PPD symptoms. They showed that plasma oxytocin level significantly predicted PPD symptoms 2 weeks after delivery. Also, they found a significant correlation between oxytocin level and the gestational age at delivery.[16] Although the settings of the procedure between (Skrundz,2011) and ours were very similar, we did not find the inverse correlation between oxytocin and PPD symptoms, nor we found any relation between oxytocin and gestational age at delivery. This variance might be attributed to the difference in the number of participants (74:172), difference in the ethnic groups of participants (Switzerland: Jordan), difference of cut-point levels of EPDS (10:13), and difference of the time of assessment of PPD symptoms (2 weeks: 4 to 6 weeks).

In comparison with (Eapen,2014), they found a significant inverse correlation between oxytocin and depression. [17] However, this correlation was drawn between serum oxytocin 3 months after delivery with antenatal and postnatal depression. On the other hand, the significant correlation was lost when the test was conducted between antenatal oxytocin and postpartum depression, ending up with a similar result to ours.

In short, the results obtained by our work and by the aforementioned works testing the association between antenatal oxytocin and PPD are generally inconclusive. This conclusion was previously suggested by two recent systemic reviews by (Moura, 2016; Thul, 2020) testing the association between antenatal and postnatal oxytocin concentration with PPD symptoms. $[19,20]$ Here in, we are commenting on the inconsistency between the results and why it is not recommended yet to use antenatal serum oxytocin level alone in the prediction of PPD symptoms. First, (Skrundz, 2011) and (Massey, 2016) ended up with contradictory results, although they both found a correlation between antenatal oxytocin and PPD symptoms. By the time (Massey, 2016) suggested a positive correlation between oxytocin and PPD among women with previous major depressive disorders, (Skrundz, 2011) found a negative correlation. $[16,18]$ Second, (Massey, 2016) found no correlation at first between oxytocin and PPD symptoms, while a direct significant association appeared only among high risk group. This finding is suggesting that oxytocin alone was not capable of predicting PPD, it has needed another factor to interact with it before predicting PPD.

At the same time, it is illogical to ignore all the available evidence showing the link between oxytocin with maternal behavior, mother-infant bonding, and stress related disorders. [21, 22] Therefore, we are proposing few possible available theories that might be able to explain the disintegration between peripheral oxytocin level and its effect centrally. First, (Cyranowski, 2012) suggested that peripheral oxytocin may have a dysregulated pattern of release in denresced women 1231 Sernnd the cenetic variation in the oxytocin receptor gene may play a role in modulating the response of different candidates Loading [MathJax]/jax/output/CommonHTML/jax.js

Page $8 / 12$ 
to the same stimuli, as suggested by (Chen, 2011) and (Jonas 2013). [24, 25] Third, there may be different signals that alter the oxytocin physiological response. This theory was suggested by (Stubue, 2013) after they found that breast feeding had intensified the relation between oxytocin and PPD. [26]

Our study also showed that unlike oxytocin level, there was a statistically significant correlation between PPD and below Bachelor`s degree level of education, below 1000 Jordanian Dinars ( $\approx 1400$ US Dollars) family monthly income, positive family history of depression, positive family issues, a previous history of depression, and absent emotional family support. In fact, association between PPD was a lifetime previous history of depression was noticeable.

Edinburgh Postnatal Depression Scale (EPDS) is the most commonly used validated screening tool for postpartum depression. [15, 27] Many scientific bodies are using it with different degrees of recommendations, where defining a clinically significant cut-off point is the most debatable factor. A score of 13 and above is the most widely used score to define probable depression. [28] We have used 13 as the cut-off point to keep standards consistent with the previously conducted study in 2006 in northern Jordan (the same region of our work) which showed the prevalence of PPD at 22.1\%.[2] Our study has shown an alarming rise in the prevalence of PPD to $30.8 \%$ over nearly 13 years in the same place and among the same population. It is important to notice here that using a higher cut-off point may increase the specificity at the expense on the sensitivity. Of the total cohort, 13 participants (out of 172, representing 7.5\%) admitted that they had had thoughts of harming themselves at different frequencies. One of them, had these thoughts quit often.

To the best of our knowledge, this study is the fourth study that looked at the prediction of PPD symptoms in the first three months after delivery by the third trimester serum oxytocin level, after (Skrundz, 2011; Eapen, 2014; Massy, 2016). Also, this study is the first-of-its-kind that tests the capability of predicting PPD symptoms by antenatal serum oxytocin concentration among Middle Eastern women. Furthermore, our sample is the biggest sample used, consisted of 172 participants.

There were some limitations in the study. The first limitation is that the sample was collected from a single hospital where most women descended from the same ethical, social and environmental background. Therefore, it is difficult to generalize the findings from a single region to be applied on all women. Hence, we advise future researches to collect a sample from different places for better understanding of the physiological changes of oxytocin among different ethnic groups. The second limitation is that EPDS, the most widely used tool for defining PPD symptoms, has limited sensitivity and specificity. For example, a recent estimate of the positive predictive value of EPDS was around $62 \%$, which means that about $38 \%$ of women scoring $>13$ on the EPDS were incorrectly diagnosed as having major depression. [29]

\section{Conclusion.}

There was no relation between late antenatal third trimester serum oxytocin level and early-onset postpartum depression symptoms. Antenatal serum oxytocin level alone was not capable of predicting early onset postpartum depression. The study also highlights the importance of the socioeconomic factors including education, income, personal and family history of depression, and family support in terms of identifying women at risk of suffering from PPD in the early postpartum period.

\section{Declarations}

\section{Ethics approval and consent to participate:}

Ethical approval for this prospective study was granted by the IRB committee at King Abdulla University Hospital. Reference number: (48/116/2016) on $31 / 05 / 2018$. All participants had completed and signed an informed consent for participation. Consents were kept safe and ready to be provided upon request.

\section{Consent to publication:}

We acknowledge that the manuscript represents original work and has been submitted solely to the BMC pregnancy and childbirth Journal and all authors give the publisher the permission to publish the work.

\section{Code of Ethics:}

The work was carried out in accordance with The Code of Ethics of the World Medical Association (Declaration of Helsinki).

\section{Availability of data and material:}

The data that support the findings of this study are available from King Abdulla University Hospital (KAUH) [Third party]. Restrictions apply to the availability of these data, which were used under license for this study. Data are available [From the corresponding author, Hasan Rawashdeh] with the permission of the IRB committee at KAUH [Third party].

Loading [MathJax]/jax/output/CommonHTML/jax.js 


\section{Competing interests:}

The authors declare that they have no competing interests.

\section{Declarations of interest:}

None.

\section{Funding:}

This work was funded by the Deanship of Research at Jordan University of Science and Technology. Their role was limited to laboratory analysis expenses. The sponsor had no role in collection and interpretation of data, in the writing of the report, and in the decision to submit the article for publication.

\section{Authors' contribution:}

- R: Conceptualization, Data curation, Formal Analysis, Funding acquisition, Investigation, Methodology, Project administration, Resources, Supervision, Validation, Writing - original draft, and Writing - review \& editing.

- Z.A: Conceptualization, Data curation, Formal Analysis, Validation and Writing - review \&editing, and Resources.

- S: Conceptualization, Data curation, Investigation, Formal Analysis, and Supervision.

- R.A: Data curation, Formal Analysis, Project administration, and Resources.

- M.A: Investigation, Methodology, Validation and Writing - review \&editing.

- All authors read and approved the final manuscript.

\section{Acknowledgments:}

This work was approved and sponsored by the Deanship of Research at Jordan University of Science and Technology, under project grant number (20180434). We are very thankful for the staff at King Abdulla University Hospital for their cooperation during conducting the work, especially nurses at the antenatal clinics and technicians at the laboratories.

\section{References}

1. Gmitrowicz A, Kucharska A. [Developmental disorders in the fourth edition of the American classification: diagnostic and statistical manual of mental disorders (DSM IV - optional book)]. Psychiatr Pol. 1994;28:509-21. https://www.ncbi.nlm.nih.gov/pubmed/7527563.

2. Mohammad KI, Gamble J, Creedy DK. Prevalence and factors associated with the development of antenatal and postnatal depression among Jordanian women. Midwifery. 2011;27:e238-45.

3. Ozcan NK, Boyacioglu NE, Dinc H. Postpartum Depression Prevalence and Risk Factors in Turkey: A Systematic Review and Meta-Analysis. Arch Psychiatr Nurs. 2017;31:420-8.

4. Chaaya M, Campbell OM, El Kak F, Shaar D, Harb H, Kaddour A. Postpartum depression: prevalence and determinants in Lebanon. Arch Womens Ment Heal. 2002;5:65-72.

5. Davis NL, Smoots AN, Goodman DA. Pregnancy-related deaths: data from 14 US Maternal Mortality Review Committees, 2008-2017. 2019.

6. Dayan J, Creveuil C, Marks MN, Conroy S, Herlicoviez M, Dreyfus M, et al. Prenatal depression, prenatal anxiety, and spontaneous preterm birth: a prospective cohort study among women with early and regular care. Psychosom Med. 2006;68:938-46.

7. Bauman BL, Ko JY, Cox S, D’Angelo D V, Warner L, Folger S, et al. Vital Signs: Postpartum Depressive Symptoms and Provider Discussions About Perinatal Depression-United States, 2018. Morb Mortal Wkly Rep. 2020;69:575.

8. Chen C, Gao J, Zhang J, Jia L, Yu T, Zheng Y. Serum leptin level measured $48 \mathrm{~h}$ after delivery is associated with development of postpartum depressive symptoms: a 3-month follow-up study. Arch Womens Ment Heal. 2016;19:1001-8.

9. Fung J, Gelaye B, Zhong QY, Rondon MB, Sanchez SE, Barrios Y V, et al. Association of decreased serum brain-derived neurotrophic factor (BDNF) concentrations in early pregnancy with antepartum depression. BMC Psychiatry. 2015;15:43.

10. Ramachandran Pillai R, Sharon L, Premkumar NR, Kattimani S, Sagili H, Rajendiran S. Luteinizing hormone-follicle stimulating hormone ratio as biological predictor of post-partum depression. Compr Psychiatry. 2017;72:25-33.

11. Skrundz M, Bolten M, Nast I, Hellhammer DH, Meinlschmidt G. Plasma oxytocin concentration during pregnancy is associated with development of Loading [MathJax]/jax/output/CommonHTML/jax.js '..'irmacology. 2011;36:1886-93.

Page $10 / 12$ 
12. Macdonald K, Macdonald TM. The peptide that binds: a systematic review of oxytocin and its prosocial effects in humans. Harv Rev Psychiatry. 2010;18:1-21.

13. Cochran DM, Fallon D, Hill M, Frazier JA. The role of oxytocin in psychiatric disorders: a review of biological and therapeutic research findings. Harv Rev Psychiatry. 2013;21:219-47.

14. Faul F, Erdfelder E, Lang A-G, Buchner A. G* Power 3: A flexible statistical power analysis program for the social, behavioral, and biomedical sciences. Behav Res Methods. 2007;39:175-91.

15. Ghubash R, Abou-Saleh MT, Daradkeh TK. The validity of the Arabic Edinburgh Postnatal Depression Scale. Soc Psychiatry Psychiatr Epidemiol. 1997;32:474-6.

16. Skrundz M, Bolten M, Nast I, Hellhammer DH, Meinlschmidt G. Plasma oxytocin concentration during pregnancy is associated with development of postpartum depression. Neuropsychopharmacology. 2011;36:1886-93.

17. Eapen V, Dadds M, Barnett B, Kohlhoff J, Khan F, Radom N, et al. Separation anxiety, attachment and inter-personal representations: disentangling the role of oxytocin in the perinatal period. PLoS One. 2014;9:e107745.

18. Massey SH, Schuette SA, Pournajafi-Nazarloo H, Wisner KL, Carter CS. Interaction of oxytocin level and past depression may predict postpartum depressive symptom severity. Arch Womens Ment Heal. 2016;19:799-808.

19. Thul TA, Corwin EJ, Carlson NS, Brennan PA, Young LJ. Oxytocin and postpartum depression: A systematic review. Psychoneuroendocrinology. 2020;:104793.

20. Moura D, Canavarro MC, Figueiredo-Braga M. Oxytocin and depression in the perinatal period-a systematic review. Arch Womens Ment Heal. 2016;19:561-70.

21. Feldman R, Weller A, Zagoory-Sharon O, Levine A. Evidence for a Neuroendocrinological Foundation of Human Affiliation:Plasma Oxytocin Levels Across Pregnancy and the Postpartum Period Predict Mother-Infant Bonding. Psychol Sci. 2007;18:965-70. doi:10.1111/j.1467-9280.2007.02010.x.

22. Neumann ID, Landgraf R. Balance of brain oxytocin and vasopressin: implications for anxiety, depression, and social behaviors. Trends Neurosci. 2012;35:649-59.

23. Cyranowski JM, Hofkens TL, Frank E, Seltman H, Cai HM, Amico JA. Evidence of dysregulated peripheral oxytocin release among depressed women. Psychosom Med. 2008;70:967-75.

24. Chen FS, Kumsta R, von Dawans B, Monakhov M, Ebstein RP, Heinrichs M. Common oxytocin receptor gene (OXTR) polymorphism and social support interact to reduce stress in humans. Proc Natl Acad Sci U S A. 2011;108:19937-42.

25. Jonas W, Mileva-Seitz V, Girard AW, Bisceglia R, Kennedy JL, Sokolowski M, et al. Genetic variation in oxytocin rs 2740210 and early adversity associated with postpartum depression and breastfeeding duration. Genes Brain Behav. 2013;12:681-94.

26. Stuebe AM, Grewen K, Meltzer-Brody S. Association between maternal mood and oxytocin response to breastfeeding. J Womens Heal. 2013;22:352-61. doi:10.1089/jwh.2012.3768.

27. Cox JL, Holden JM, Sagovsky R. Detection of postnatal depression. Development of the 10-item Edinburgh Postnatal Depression Scale. Br J Psychiatry. 1987;150:782-6.

28. Evans J, Heron J, Francomb H, Oke S, Golding J. Cohort study of depressed mood during pregnancy and after childbirth. Bmj. 2001;323:257-60.

29. Milgrom J, Mendelsohn J, Gemmill AW. Does postnatal depression screening work? Throwing out the bathwater, keeping the baby. J Affect Disord. 2011;132:301-10.

\section{Figures}


Interviewed, screened, and consented

women for participation $(\mathrm{N}=211)$

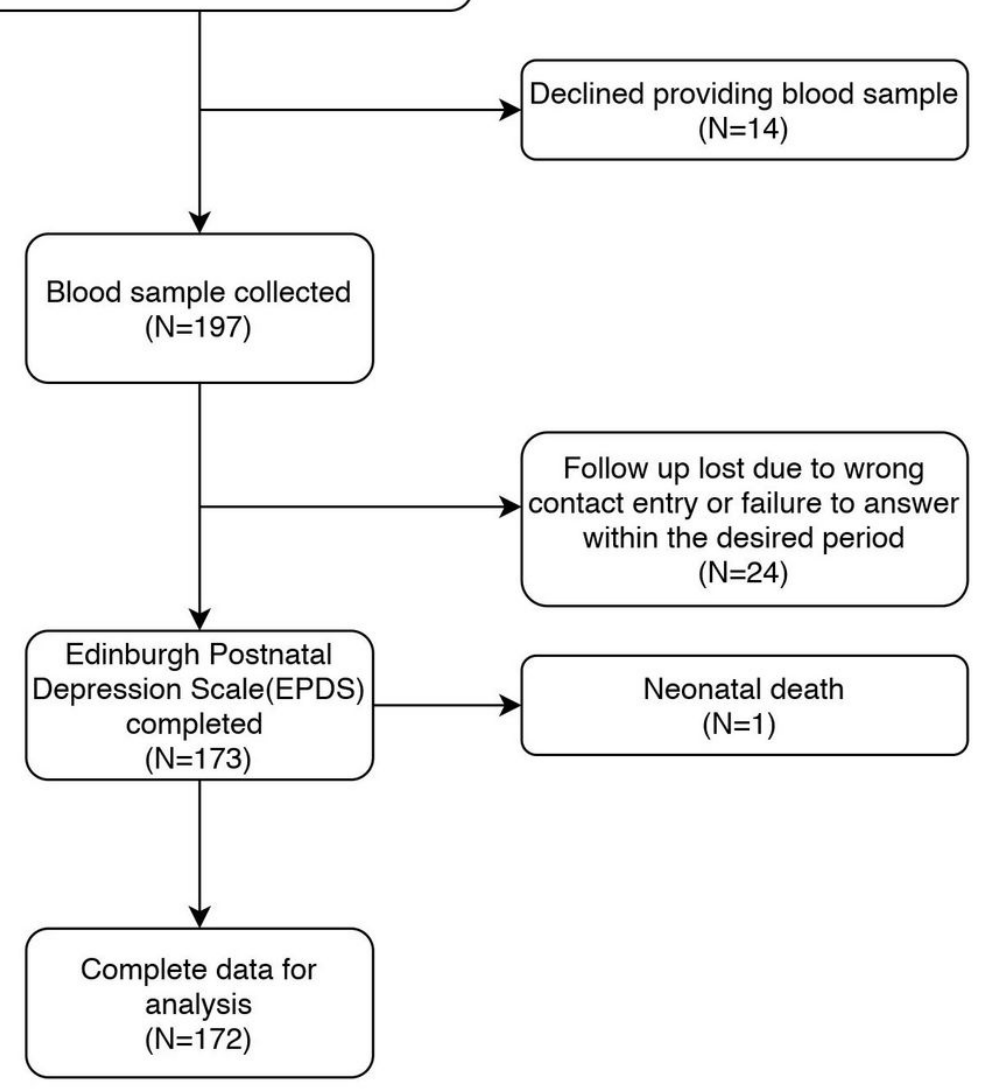

Figure 1

A flowchart of participants 